\title{
SUBSTITUSI FILLER DENGAN LIMBAH KARBIT TERHADAP CAMPURAN ASPAL PANAS HOT ROLLED SHEET - BASE COURSE (HRS-BC)
}

\author{
Putri Devi Pratiwi ${ }^{1}$ dan Dwi Kartikasari ${ }^{2}$ \\ ${ }^{1}$ Program Studi Teknik Sipil Fakultas Teknik, Universitas Islam Lamongan, Jl. Veteran No. 53 A Lamongan \\ putridevipratiwi79@gmail.com \\ ${ }^{2}$ Dosen Jurusan Teknik Sipil Fakultas Teknik, Universitas Islam Lamongan, Jl. Veteran No. 53 A Lamongan \\ dkartika27@gmail.com
}

\begin{abstract}
In hot asphalt mixtures, fillers are used, fillers are used as fillers between coarser aggregate particles, fillers also function to increase the binding energy (cohesion) of asphalt concrete. This study uses waste carbide as an alternative to filler in the HRS-BC asphalt mixture, this study aims to determine the results of the Marshall test, namely stability, VFWA, VMA, VIM, Flow, and MQ. This research uses experimental research method. Composition Variation The substitution of carbide waste used is $0 \%, 40 \%, 50 \%$, and $60 \%$ of the weight of the filler. The results of the study obtained a mixture of $0 \%$ carbide waste with stability values of $871.13 \mathrm{~kg}$, VFWA $75.18 \mathrm{~kg}$, VMA 22.55 $\mathrm{kg}$, VIM $7.01 \mathrm{~kg}$, flow $3.80 \mathrm{~mm}$, MQ 229.29. variation 40\% stability value is $629.20 \mathrm{~kg}$, VFWA $65.69 \mathrm{~kg}$, VMA 25.09 $\mathrm{kg}$, VIM $10.05 \mathrm{~kg}$, flow $2.85 \mathrm{~mm}, M Q 226.52$. variation of $50 \%$ stability value is $1011.76 \mathrm{~kg}$, VFWA $72.75 \mathrm{~kg}, V M A$ $23.15 \mathrm{~kg}$, VIM $7.72 \mathrm{~kg}$, flow $2.50 \mathrm{~mm}, M Q 410.00$. variation of $60 \%$ stability value is $1291.26 \mathrm{~kg}$, VFWA $71.67 \mathrm{~kg}$, VMA $23.41 \mathrm{~kg}, V I M 8.04 \mathrm{~kg}$, flow $2.30 \mathrm{~mm}, M Q$ value 562.35 . from the results of the study it can be concluded that the use of carbide waste at a variation of $60 \%$ is the most effective mixture according to the General Specifications Division 6: 2016 Asphalt Pavement.
\end{abstract}

Keywords: Fillers; HRS-BC; Carbide Waste; Marshall Test

\begin{abstract}
ABSTRAK
Dalam campuran aspal panas digunakan bahan pengisi filler,Filler digunakan sebagai bahan pengisi antar partikel agregat yang lebih kasar,filler juga berfungsi meningkatkan energi ikat (kohesi) pada aspal beton. penelitian ini menggunakan limbah karbit sebagai alternatif pengganti filler pada campuran aspal HRS-BC, penelitian ini bertujuan untuk mengetahui hasil pengujian marshall test yaitu stabilitas,VFWA,VMA,VIM,Flow, dan MQ. Penelitian ini menggunakan metode penelitian Eksperimen. Komposisi Variasi Substitusi limbah karbit yang digunakan sebesar $0 \%, 40 \%, 50 \%$, dan $60 \%$ dari berat filler. hasil penelitian didapatkan campuran limbah karbit variasi $0 \%$ nilai stabilitas sebesar $871,13 \mathrm{~kg}$, VFWA $75,18 \mathrm{~kg}$, VMA 22,55 kg, VIM 7,01 kg, flow 3,80 mm, MQ 229,29. variasi 40\% nilai stabilitas sebesar 629,20 kg, VFWA 65,69 kg, VMA 25,09 kg, VIM 10,05 kg, flow 2,85 mm, MQ 226,52. variasi 50\% nilai stabilitas sebesar 1011,76 kg, VFWA 72,75 kg, VMA 23,15 kg, VIM 7,72 kg, flow 2,50 mm, MQ 410,00. variasi 60\% nilai stabilitas sebesar 1291,26 kg, VFWA 71,67 kg, VMA 23,41 kg, VIM $8,04 \mathrm{~kg}$, flow $2,30 \mathrm{~mm}$, nilai MQ 562,35. dari hasil penelitian dapat disimpulkan bahwa penggunaan limbah karbit pada variasi $60 \%$ adalah campuran yang paling efektif sesuai Spesifikasi Spesifikasi Umum Divisi 6 : 2016 Perkerasan Aspal.
\end{abstract}

Kata kunci: Filler; HRS-BC; Limbah Karbit; Marshall Test

\section{PENDAHULUAN}

\section{Latar belakang}

Saat ini inovasi campuran aspal diindonesia mengalami perkembangan yang cukup pesat dari reuse dan reduce menggunakan alternatif bahan pengganti / bahan tambah yang bertujuan untuk peningkatan kualitas perkerasan jalan raya dan bertambahnya nilai ekonomis dari bahan yang tak terpakai seperti limbah karbit. Didaerah kabupaten lamongan, banyak dijumpai bengkel las karbit yang pada umumnya tidak dilakukan pengolahan kembali terhadap limbah las karbit tersebut. Limbah las karbit ini didapatkan dari proses penyambungan logam dengan logam (pengelasan) yang menggunakan karbit (gas aseteline $=\mathrm{C} 2 \mathrm{H} 2$ ) sebagai bahan bakar yang mengandung zat berbahaya dan dapat menyebabkan pencemaran lingkungan. 
Seiring dengan perkembangan inovasi terhadap bahan campuran aspal yang pesat, solusi pengurangan Limbah karbit yang sebelumnya hanya menjadi tumpukan dan dibuang di area sekitar bengkel las karbit adalah dengan cara melakukan pemanfaatan kembali limbah karbit sebagai Filler pada campuran aspal panas. sama halnya seperti semen, limbah karbit mengandung kapur $(\mathrm{CaO})$ dan silika yang cukup tinggi. Limbah karbit mengandung sekitar $60 \%$ unsur kalsium sehingga limbah karbit dapat digunakan sebagai filler dalam campuran aspal. Filler penggunaannya dalam campuran beton aspal sangat sedikit, namun manfaatnya sangatlah baik. Filler digunakan sebagai bahan pengisi antar partikel agregat yang lebih kasar, sehingga udara menjadi lebih kecil serta menghasilkan tahanan gesek dan penguncian antar butiran yang lebih tinggi. dengan demikian stabilitas campuran semakin meningkat. Disamping itu filler dapat berfungsi meningkatkan energi ikat (kohesi) pada aspal beton.

Penggunaan limbah karbit dapat meningkatkan kinerja aspal karena mempengaruhi karakteristik campuran, seperti ketahanan deformasi serta persentase rongga. Berdasarkan uraian diatas, penulis melakukan penelitian tentang hal tersebut yaitu penggantian filler dengan limbah karbit. Tujuan Penelitian ini adalah untuk mengetahui hasil dari pengujian marshall pada aspal HRS-BC dan mengetahui secara umum pengaruh penggunaan limbah karbit sebagai substitusi filler terhadap campuran aspal HRS-BC.

Kebanyakan peneliti terdahulu menggunakan limbah karbit sebagai campuran aspal panas jenis AC-WC dengan variasi substiusi limbah karbit sebesar $25 \%, 50 \%, 75 \%$ dan $100 \%$ dari berat filler. Hasil penelitian tersebut menunjukkan campuran terbaik adalah pada penggunaan limbah karbit kadar 50\%. penambahan limbah karbit 50\% dapat meningkatkan nilai KAO sebesar 5,89\% serta nilai stabilitas,VFWA,VIM,flow,dan MQ. Sedangkan pada penelitian ini Limbah Karbit digunakan sebagai filler pada campuran aspal HRS-BC dengan kadar limbah karbit sebesar $0 \%, 40 \%, 50 \%$ dan $60 \%$. hasil penelitian campuran terbaik terdapat pada kadar $60 \%$ yang dapat meningkatkan nilai stabilitas,VFWA,VIM,dan MQ. sedangkan penurunan terjadi pada nilai VMA dan flow.

\section{Hot Rolled Sheet (HRS)}

Menurut (Hardiyatmo, 2015), Lataston / HRS adalah lapisan penutup yang terdiri dari campuran agregat bergradasi senjang, filler, dan aspal keras dengan kandungan aspal yang lebih tinggi daripada jenis laston. pada aspal HRS Kadar aspal yang digunakan sangatlah tinggi, penggunaan kadar aspal yang tinggi bertujuan untuk memiliki kelenturan, ketahanan dan ketahanan yang lebih tinggi terhadap peleburan. campuran lataston tahan terhadap retak, tetapi rentan terhadap deformasi plastis berupa bekas roda jalan, terutama akibat lalu lintas yang padat.

Karakteristik beton aspal yang paling penting dalam campuran ini adalah keawetan dan kelenturannya. Menurut fungsinya, Lataston memiliki 2 campuran diantaranya:

1. Lataston sebagai lapisan permukaan, biasa disebut $H R S-W C$. Tebal minimum lapisan $H R S-W C$ yaitu $3 \mathrm{~cm}$.

2. Lataston sebagai lapisan pondasi, disebut HRS-Base. HRS-Base mempunyai gradasi yang lebih kasar daripada lataston $H R S-W C$. Tebal minimum lapisan HRS-Base adalah $3,5 \mathrm{~cm}$.

\section{Spesifikasi campuran Lataston}

Ketentuan sifat - sifat campuran Lataston (Hot Rolled Sheet) terdapat pada Tabel 1.

Tabel 1. Persyaratan HRS untuk kepadatan lalu lintas berat

\begin{tabular}{ccc}
\hline No & Spesifikasi & Nilai \\
\hline 1 & Jumlah Tumbukan & $75 \times 2$ \\
2 & Densitas & - \\
3 & VIM & $3-6 \%$ \\
4 & VFMA & $\geq 68 \%$ \\
5 & Stabilitas & $\geq 800 \mathrm{~kg}$ \\
6 & Flow & $\geq 3 \mathrm{~mm}$ \\
7 & Marshall Quotient & $\geq 250 \mathrm{~kg} / \mathrm{mm}$ \\
\hline (Sumber : Kementerian Pekerjaan Umum dan Perumahan Rakyat, 2016)
\end{tabular}

\section{Unsur penyusun campuran aspal panas}

\section{Aspal}

Aspal dapat didefinisikan sebagai zat berwarna hitam atau coklat tua, padat sampai agak padat pada suhu kamar. Jika dipanaskan sampai suhu tertentu maka aspal akan melunak atau menjadi cair, sehingga pada saat proses pembuatan aspal beton dapat membungkus partikel agregat pada perkerasan jalan.(Satyagraha, 2018). 


\section{Agregat}

Menurut (Hardiyatmo, 2015), Agregat adalah kumpulan batu dan pasir yang dihancurkan atau partikel mineral alami dan buatan lainnya. Lapisan perkerasan mengandung 90-95\% dari persentase berat agregat, atau 75-85\% dari persentase volume agregat. Jenis-jenis agregat dibagi menjadi beberapa bagian menurut diameter partikelnya yaitu:

a. Agregat kasar

Agregat kasar adalah agregat yang butirannya tertahan saringan no. 8 (2,36 mm).

b. Agregat halus

Agregat Halus adalah agregat yang butiranya lolos saringan No. 8 (2,36 mm) dan tertahan saringan No. 200 (diameter 0,075 mm).

c. Filler / bahan pengisi

Filler adalah bahan pengisi yang materialnya lolos saringan no. 200 (diameter 0,075 mm). digunakan sebagai pengisi antar partikel agregat kasar untuk mengecilkan pori-pori, menghasilkan tahanan gesek yang tinggi dan mengunci antar partikel, sehingga meningkatkan stabilitas campuran. .(Hardiyatmo, 2015)

\section{Limbah karbit}

Limbah Las Karbit merupakan produk gas acetylene yang melalui proses yang sangat sederhana yaitu Kalsium karbida (CaC2) bereaksi dengan air $(\mathrm{H} 2 \mathrm{O})$ menghasilkan gas asetilen $(\mathrm{C} 2 \mathrm{H} 2)$. Kalsium karbida adalah produk sampingan dari produksi gas asetilen, berbentuk padatan berwarna hitam dan putih atau abu-abu muda. Awalnya karena adanya gas dan air, limbah kalsium karbida diproduksi dalam bentuk koloid (semi cair). Setelah 3-7 hari, gas yang terkandung akan perlahan menguap saat gas dan air kapur menguap. Setelah sisa karbida yang disemen mulai mengering, akan menjadi menggumpal, rapuh dan mudah hancur, serta dapat berubah menjadi bubuk..(Mahendra $\&$ Risdiato, 2019)

Limbah Karbit didapatkan dari sisa pembakaran karbit yang tidak digunakan. sama halnya dengan semen, limbah karbit memiliki kandungan kalsium yang cukup tinggi, limbah karbit mengandung sekitar 60\% unsur kalsium, komposisi kimia limbah karbit antara lain yaitu 1,48\% SiO2, 59,98\% CaO, 0,09\% Fe2O3, 9,07\% Al2O3, 0,67\% $\mathrm{MgO}$ dan 28,71\% Unsur lain.(Zakir et al., 2020). Limbah las karbit juga dapat meningkatkan kinerja aspal karena mempengaruhi karakteristik campuran, seperti ketahanan deformasi serta persentase rongga.(Wiharto, 2015)

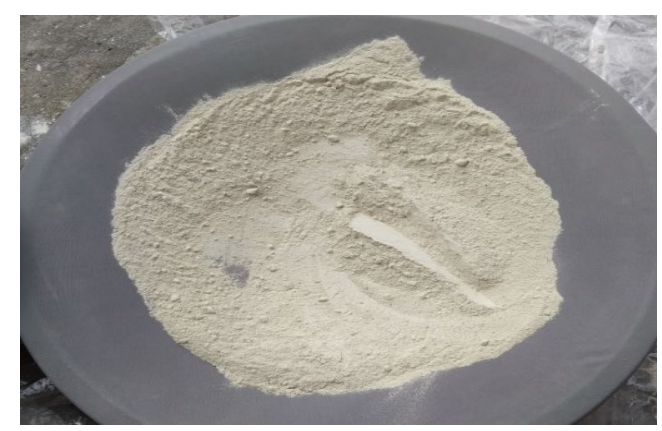

Gambar 1. Limbah karbit

\section{METODE PENELITIAN}

\section{Waktu dan lokasi penelitian}

Waktu pelaksanaan pada penelitian ini pada tanggal 16 Februari 2021 dan lokasi penelitian terletak di laboratorium program studi teknik sipil ,Universitas Islam Lamongan

\section{Tahap pengumpulan data}

1. Data primer

Dalam hal ini, peneliti mengumpulkan data primer dengan melakukan observasi dan penelitian secara langsung di labolatorium Teknik Sipil Universitas Islam Lamongan untuk mendapatkan data-data yang diperlukan secara lengkap. 


\section{Data sekunder}

Pengumpulan data dan mencari data dengan membaca buku di perpustakaan, dan jurnal yang berkaitan dengan pemanfaatan limbah karbit.

\section{Tahapan penelitian}

1. Persiapan Alat dan bahan

Bahan yang digunakan dalam penelitian ini :
a. Agregat material kasar
b. Agregat material Halus
c. Aspal penetrasi $60 / 70$
d. Filler atau bahan pengisi yaitu Portland Cement.

Peralatan yang digunakan sebagai berikut :

a. Peralatan pemeriksaan aspal

Pemeriksaan aspal menggunakan peraatan uji penetrasi, uji titik lembek, titik nyala dan titik bakar dan uji berat jenis (Piknometer)

b. Pemeriksaan aspal agregat

Satu set saringan (sieve analyisis), alat uji berat jenis (piknometer, timbangan, pemanas)

c. Pengujian karateristik campuran beraspal

Alat uji karateristik campuran beraspal yaitu alat dalam Pengujian untuk metode marshall.

2. Pengujian bahan susun campuran aspal HRS-BC

a. Pengujian berat jenis dan penyerapan air agregat kasar

Menurut (SNI 1969-2008) dilakukan Pengujian berat jenis dan penyerapan air. Pemeriksaan ini bertujuan untuk menentukan berat jenis (bulk), berat jenis kering permukaan jenuh (saturated surface dry) dan berat jenis semua (apparent) dari agregat kasar.

b. Pengujian berat jenis dan penyerapan air agregat halus

Menurut (SNI 1970-2008) dilakukan uji berat jenis dan penyerapan agregat halus. Tujuan dari pemeriksaan ini adalah untuk menentukan berat jenis Curah, kering permukaan jenuh, dan berat jenis total (semu) agregat halus.

3. Pengujian bahan aspal

a. Pengujian penetrasi aspal

Pengujian Penetrasi aspal digunakan untuk mengetahui permeabilitas aspal keras atau lunak (padat atau semi padat). Dengan memasukkan jarum penetrasi dengan ukuran tertentu, beban tertentu dan waktu tertentu, kedalaman aspal pada suhu tertentu. uji penetrasi aspal mengacu pada (SNI 2456-2011)

b. Pengujian titik lembek aspal

Pengujian Titik Lembek Aspal dapat digunakan untuk menentukan titik lembek aspal kisaran antara $30^{\circ} \mathrm{C}-$ $200^{\circ} \mathrm{C}$. Pengujian Titik lembek mengacu pada (SNI 2434-2011)

c. Pengujian titik nyala dan titik bakar aspal

Pengujian titik nyala dan titik bakar mengacu pada (SNI 2433-2011). Pengujian ini digunakan untuk menentukan titik nyala dan titik bakar aspal. Titik nyala adalah suhu nyala singkat pada suatu titik di atas permukaan aspal. Titik bakar adalah suhu di mana nyala api terlihat setidaknya selama 5 detik pada titik di atas permukaan aspal.

4. Rencana campuran / Job Mix Formula

Job mix Formula yang digunakan untuk meningkatkan mutu dari campuran aspal panas HRS-BC maka dibuatlah suatu campuran yang nantinya akan digunakan. 
a. Proses persiapan limbah karbit

Limbah Karbit diambil dari bengkel las karbit daerah kabupaten lamongan, kemudian pengolahan limbah las karbit dilakukan dengan cara mengayak menggunakan saringan sieve shaker untuk mendapatkan limbah las karbit murni. limbah las karbit yang digunakan sebagai filler adalah limbah karbit yang lolos saringan no.200.

b. Metode pencampuran limbah karbit

Metode Pencampuran Limbah Karbit yaitu aspal dipanaskan dengan suhu yang $150^{\circ} \mathrm{C}$, kemudian limbah las karbit ditambahkan pada aspal,agregat dan filler dan dilanjutkan pengadukan selama \pm 20 menit. setelah tercampur merata benda uji siap dipadatkan dengan alat compact.

Adapun Komposisi bahan penyusun campuran aspal panas yang digunakan adalah sebagai berikut:

1. Pada penelitian ini agregat yang digunakan yaitu agregat untuk campuran HRS-BC dimana agregat yang digunakan mengikuti spesifikasi SNI

2. Melakukan analisis perhitungan komposisi mengikuti persyaratan spesifikasi yag digunakan

3. Aspal yang digunakan dalam penelitian ini adalah aspal minyak dengan presentase pen 60/70 yang merupakan produk pertamina dan didapatkan dari PT. Cahaya Indah Madya Pratama.

4. Limbah Karbit digunakan berasal dari bengkel las karbit didaerah lamongan

5. Kadar Aspal yang digunakan adalah 6,5\% dengan berat aspal dari Job Mix Formula yang ditentukan.

6. Variasi untuk campuran aspal panas dengan penambahan limbah karbit adalah 40\%, 50\% dan $60 \%$ dari berat filler.

Tabel 2. Job Mix Desain campuran aspal HRS-BC

\begin{tabular}{|c|c|c|c|c|c|c|c|c|c|c|}
\hline Size & $\begin{array}{l}\text { No. } \\
\text { Sieve }\end{array}$ & $\begin{array}{r}F \\
A g g r \\
(0 \sim 5\end{array}$ & $\begin{array}{l}\text { ge } \\
\text { gate } \\
\mathrm{mm} \text { ) }\end{array}$ & $\begin{array}{r}M e \\
A g g \\
(5 \sim \\
\end{array}$ & $\begin{array}{l}\text { ium } \\
\text { egate } \\
\mathrm{mm}) \\
\end{array}$ & \multicolumn{2}{|c|}{$\begin{array}{l}\text { Coarse Aggregate } \\
(10 \sim 19 \mathrm{~mm})\end{array}$} & Filler & \multirow[t]{2}{*}{$\begin{array}{l}\text { Combined } \\
\text { Gradation }\end{array}$} & \multirow[t]{2}{*}{ Spesification } \\
\hline Sieve & $(\mathrm{mm})$ & & $54 \%$ & & $30 \%$ & & $14 \%$ & $2 \%$ & & \\
\hline $3 / 4 "$ & 19 & 100 & 54 & 100 & 30 & 99,38 & 13,91 & 2 & 99,91 & 100 \\
\hline $1 / 2 "$ & 12,5 & 100 & 54 & 99,43 & 29,83 & 75,24 & 10,53 & 2 & 96,36 & $90-100$ \\
\hline $3 / 8 "$ & 9,5 & 99,86 & 53,92 & 91,66 & 27,50 & 22,22 & 3,11 & 2 & 86,53 & $65-90$ \\
\hline$\# 4$ & 4,75 & 98,97 & 53,44 & 38,46 & 11,54 & 5,34 & 0,75 & 2 & 67,73 & - \\
\hline$\# 8$ & 2,36 & 70,98 & 38,33 & 7,27 & 2,18 & 2,30 & 0,32 & 2 & 42,84 & $35-55$ \\
\hline \# 16 & 1,18 & 43,33 & 23,40 & 4,70 & 1,41 & 2,19 & 0,31 & 2 & 27,12 & - \\
\hline \# 30 & 0,600 & 21,74 & 11,74 & 4,11 & 1,23 & 2,08 & 0,29 & 2 & 15,26 & $15-35$ \\
\hline \# 50 & 0,300 & 4,88 & 2,64 & 3,60 & 1,08 & 1,98 & 0,28 & 2 & 5,99 & - \\
\hline \# 100 & 0,150 & 3,68 & 1,99 & 2,93 & 0,88 & 1,86 & 0,26 & 2 & 5,13 & - \\
\hline$\# 200$ & 0,075 & 3,27 & 1,77 & 2,33 & 0,70 & 1,73 & 0,24 & 2 & 4,71 & $2-9$ \\
\hline
\end{tabular}

5. Analisis pengujian Marshall

Pengujian marshall test dilakukan untuk mengetahui pengaruh substitusi limbah karbit dalam campuran terhadap nilai nilai marshall properties yaitu Stabilitas Marshall, VFWA, VIM, Flow, dan Marshall Quotient (MQ).

\section{HASIL DAN PEMBAHASAN}

\section{Hasil pemeriksaan berat jenis dan penyerapan agregat}

Hasil pengujian material agregat Kasar, Sedang dan Halus ditunjukkan pada Tabel 3. 
Tabel 3. Hasil pemeriksaan material agregat kasar, agregat sedang, dan agregat halus

\begin{tabular}{|c|c|c|c|c|c|}
\hline No & Jenis Pemeriksaan & Metode Pengujian & $\begin{array}{c}\text { Hasil } \\
\text { Pengujian }\end{array}$ & Syarat & Keterangan \\
\hline 1 & Agregat Kasar & & & & \\
\hline- & Berat jenis bulk & SNI 1969-2008 & 2,61 & $\geq 2,5$ & Memenuhi \\
\hline- & Berat Jenis SSD & SNI 1969-2008 & 2,66 & $\geq 2,5$ & Memenuhi \\
\hline- & Berat Jenis Semu & SNI 1969-2008 & 2,75 & $\geq 2,5$ & Memenuhi \\
\hline- & Penyerapan Air & SNI 1969-2008 & 1,93 & $\leq 2,5 \%$ & Memenuhi \\
\hline 2 & Agregat Sedang & & & & \\
\hline- & Berat jenis bulk & SNI 1969-2008 & 2,66 & $\geq 2,5$ & Memenuhi \\
\hline- & Berat Jenis SSD & SNI 1969-2008 & 2,72 & $\geq 2,5$ & Memenuhi \\
\hline- & Berat Jenis Semu & SNI 1969-2008 & 2,84 & $\geq 2,5$ & Memenuhi \\
\hline- & Penyerapan Air & SNI 1969-2008 & 2,40 & $\leq 2,5 \%$ & Memenuhi \\
\hline 3 & Agregat Halus & & & & \\
\hline- & Berat jenis bulk & SNI 1970-2008 & 2,57 & $\geq 2,5$ & Memenuhi \\
\hline- & Berat Jenis SSD & SNI 1970-2008 & 2,65 & $\geq 2,5$ & Memenuhi \\
\hline- & Berat Jenis Semu & SNI 1970-2008 & 2,87 & $\geq 2,5$ & Memenuhi \\
\hline- & Penyerapan Air & SNI 1970-2008 & 2,87 & $\leq 3 \%$ & Memenuhi \\
\hline
\end{tabular}

\section{Pengujian aspal}

Aspal keras produksi pertamina penetrasi 60/70 yang digunakan dalam penelitian ini. Hasil pengujian aspal pen 60/70 dapat dilihat pada Tabel 4.

Tabel 4. Hasil pengujian aspal pen $60 / 70$

\begin{tabular}{lllcccc}
\hline No & Jenis Pemeriksaan & Metode Pengujian & \multicolumn{2}{c}{ Spesifikasi } & Hasil Pengujian & Keterangan \\
\hline 1 & & & Min & Max & Memenuhi \\
2 & Penetrasi Aspal & SNI 2456-2011 & 60 & 79 & 67 & Memenuhi \\
3 & Titik Nyala & SNI 2433-2011 & $200^{\circ} \mathrm{C}$ & - & 329 & Memenuhi \\
4 & Titik Lembek & SNI 2433-2011 & $300^{\circ} \mathrm{C}$ & - & 334 & Memenuhi \\
5 & Berat Jenis Aspal & SNI 2434-2011 & $48^{\circ} \mathrm{C}$ & $58^{\circ} \mathrm{C}$ & 53 & Memenuhi \\
\hline
\end{tabular}

\section{Perhitungan kadar aspal}

Untuk menghitung kadar aspal optimum sebagai bahan campuran diperoleh dari perhitungan sebagai berikut :

$$
\begin{array}{ll}
\text { Kao } & =0,035 \times \mathrm{CA}+0,045 \times \mathrm{FA}+0,18 \times \text { Filler }+\mathrm{K} \\
\mathrm{Kao} & =0,035 \times 3,04+0,045 \times(72,68+0,41)+0,18 \times 0,41+3 \\
\mathrm{Kao} & =6,46 \\
\mathrm{Kao} & =6,5 \%
\end{array}
$$

Keterangan :

CA : Agregat kasar dengan nomor ayakan tertahan 8

FA : Agregat halus total melewati saringan nomor 8 dan tertahan nomor. 200

F : Filler agregat halus tertahan no. 200

K : Nilai Konstanta 3,0

Dengan demikian kadar aspal yang digunakan dalam penelitian ini adalah $6,5 \%$. 


\section{Komposisi campuran aspal HRS-BC}

Setelah didapatkan prosentase masing-masing agregat dan perbandingan aspal, tentukan berat material mix design dan kapasitas cetakan (mould) yang ada. job mix masing-masing varian campuran aspal HRS-BC dengan limbah karbit ditunjukkan pada Tabel 5.

Tabel 5. Komposisi campuran aspal HRS-BC setiap variasi limbah karbit

\begin{tabular}{|c|c|c|c|c|c|c|c|c|}
\hline \multirow[t]{2}{*}{$\begin{array}{l}\text { Kadar } \\
\text { Aspal }\end{array}$} & \multirow{2}{*}{$\begin{array}{c}\text { Kadar } \\
\text { Limbah } \\
\text { Karbit }\end{array}$} & \multirow{2}{*}{$\begin{array}{c}\text { Berat } \\
\text { Limbah } \\
\text { Karbit }\end{array}$} & \multirow[t]{2}{*}{$\begin{array}{l}\text { Berat } \\
\text { Aspal }\end{array}$} & $\begin{array}{c}\text { Coarse } \\
\text { Aggregate }\end{array}$ & $\begin{array}{c}\text { Medium } \\
\text { Aggregate }\end{array}$ & $\begin{array}{c}\text { Fine } \\
\text { Aggregate }\end{array}$ & Filler & \multirow[t]{2}{*}{ Total } \\
\hline & & & & $54 \%$ & $30 \%$ & $14 \%$ & $2 \%$ & \\
\hline$\%$ & $\%$ & $\mathrm{Gr}$ & $\mathrm{Gr}$ & $\mathrm{Gr}$ & $\mathrm{Gr}$ & $\mathrm{Gr}$ & $\mathrm{Gr}$ & Gr \\
\hline 6,5 & 0 & 0,00 & 75,51 & 157,1 & 336,6 & 605,9 & 22,4 & 1200 \\
\hline 6,5 & 0 & 0,00 & 75,70 & 157,1 & 336,6 & 605,9 & 22,4 & 1200 \\
\hline 6,5 & 0 & 0,00 & 74,86 & 157,1 & 336,6 & 605,9 & 22,4 & 1200 \\
\hline 6,5 & 40 & 8,96 & 73,80 & 157,1 & 336,6 & 605,9 & 13,44 & 1200 \\
\hline 6,5 & 40 & 8,96 & 75,84 & 157,1 & 336,6 & 605,9 & 13,44 & 1200 \\
\hline 6,5 & 40 & 8,96 & 75,90 & 157,1 & 336,6 & 605,9 & 13,44 & 1200 \\
\hline 6,5 & 50 & 11,2 & 75,60 & 157,1 & 336,6 & 605,9 & 11,2 & 1200 \\
\hline 6,5 & 50 & 11,2 & 76,54 & 157,1 & 336,6 & 605,9 & 11,2 & 1200 \\
\hline 6,5 & 50 & 11,2 & 76,12 & 157,1 & 336,6 & 605,9 & 11,2 & 1200 \\
\hline 6,5 & 60 & 13,44 & 75,15 & 157,1 & 336,6 & 605,9 & 8,96 & 1200 \\
\hline 6,5 & 60 & 13,44 & 76,28 & 157,1 & 336,6 & 605,9 & 8,96 & 1200 \\
\hline 6,5 & 60 & 13,44 & 73,51 & 157,1 & 336,6 & 605,9 & 8,96 & 1200 \\
\hline
\end{tabular}

Campuran kerja dibuat untuk setiap satu kali cetakan sesuai dengan kebutuhan bahan yang telah direncanakan. kadar aspal yang digunakan sebesar $6,5 \%$ dari berat aspal. sementara itu, besarnya substitusi limbah karbit terhadap filler sangatlah bervariasi yaitu $40 \%, 50 \%$ dan $60 \%$.

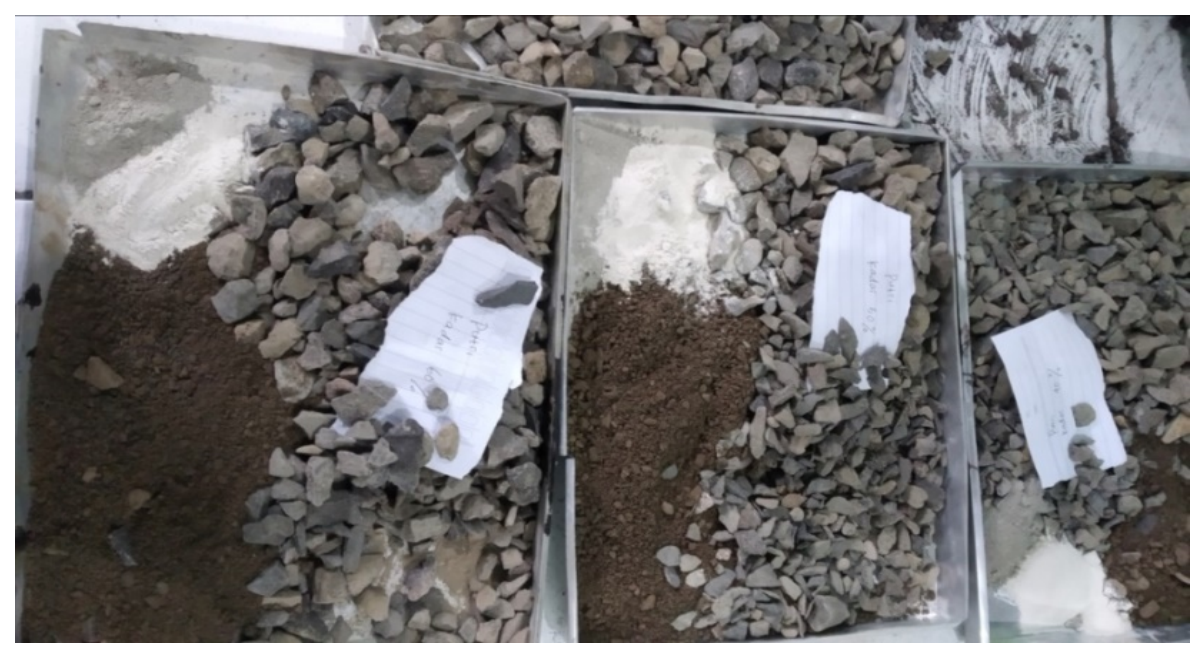

Gambar 2. Komposisi job mix aspal $H R S-B C$ 


\section{Pengujian Marshall}

Hasil pengujian substitusi filler dengan penggunaan limbah karbit campuran aspal panas HRS-BC dapat dilihat pada Tabel 6.

Tabel 6. Hasil pengujian Marshall Test rata-rata dengan limbah karbit pengganti filler

\begin{tabular}{ccccccc}
\hline $\begin{array}{c}\text { Limbah Karbit } \\
(\%)\end{array}$ & $\begin{array}{c}\text { Stabilitas } \\
(\mathrm{kg})\end{array}$ & $\begin{array}{c}\text { VFWA } \\
(\mathrm{kg})\end{array}$ & $\begin{array}{c}\text { VMA } \\
(\mathrm{kg})\end{array}$ & $\begin{array}{c}\text { VIM } \\
(\mathrm{kg})\end{array}$ & $\begin{array}{c}\text { Flow } \\
(\mathrm{mm})\end{array}$ & $\begin{array}{c}\text { MQ } \\
\mathrm{kg} / \mathrm{mm}\end{array}$ \\
\hline $0 \%$ & 871,13 & 75,18 & 22,55 & 7,01 & 3,80 & 229,29 \\
$40 \%$ & 629,20 & 65,69 & 25,09 & 10,05 & 2,85 & 226,52 \\
$50 \%$ & 1011,76 & 72,75 & 23,15 & 7,72 & 2,50 & 410,00 \\
$60 \%$ & 1291,26 & 71,67 & 23,41 & 8,04 & 2,30 & 562,35 \\
\hline
\end{tabular}

\section{Tinjauan penggantian limbah karbit terhadap stabilitas}

Hasil pengujian stabilitas penggunaan Limbah karbit dengan variasi $0 \%, 40 \%, 50 \%$ dan 60\% dari berat filler pada campuran aspal HRS-BC Secara umum memperlihatkan peningkatan dan penurunan nilai stabilitas seiring dengan Variasi kadar limbah karbitnya. adapun hubungan antara stabilitas marshall dengan limbah karbit dapat dilihat pada Gambar 3.

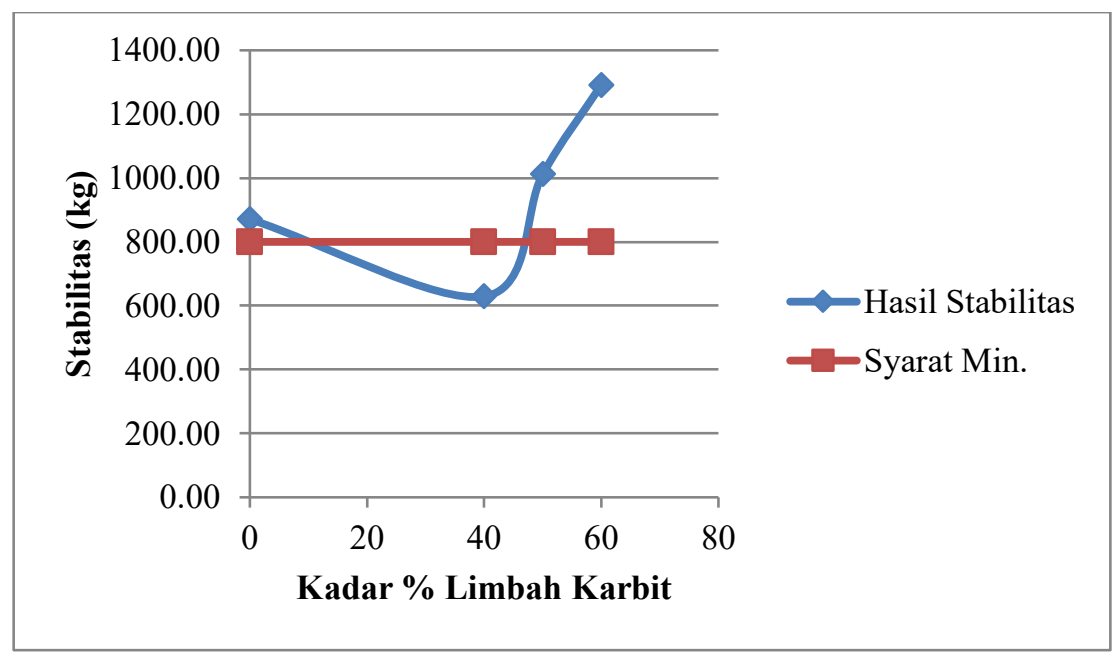

Gambar 3. Grafik hubungan antara stabilitas marshall dengan limbah karbit

Grafik diatas Menunjukkan bahwa substitusi limbah karbit mempengaruhi nilai stabilitas dan dari hasil percobaan pada variasi $40 \%$ nilai variasi mengalami penurunan, sedangkan pada kadar $50 \%-60 \%$ nilai stabilitas mengalami peningkatan. sementara untuk ketentuan dan syarat dari stabilitas marshall minimal $800 \mathrm{~kg}$. sehingga stabilitas marshall dari filler yang telah disubstitusi dengan limbah karbit pada kadar $40 \%$ tidak memenuhi Standart Spesifikasi Umum Divisi 6 : Perkerasan Aspal . sedangkan stabilitas marshall pada kadar 50\% dan 60\% telah memenuhi Standart Spesifikasi Umum Divisi 6 : Perkerasan Aspal.

Kenaikan nilai stabilitas dipengaruhi oleh beberapa faktor seperti susunan agregat dalam campuran terselimuti aspal secara merata dan saling mengunci secara sempurna (interlocking) antara bahan susun, aspal dan bahan pengganti. sehingga nilai stabilitas menunjukkkan kenaikan diantara variasi kadar limbah karbit yang lainnya. penurunan yang terjadi dalam nilai stabilitas dapat dipengaruhi oleh volume antara agregat yang terlalu tinggi dan penguncian antara partikelnya yang kurang merata.

\section{Tinjauan penggantian limbah karbit terhadap Void in the minerale aggregate (VMA)}

Hasil pengujian Void in the minerale aggregate (VMA) penggunaan Limbah karbit dengan variasi $0 \%, 40 \%, 50 \%$ dan $60 \%$ dari berat filler pada campuran aspal HRS-BC memperlihatkan peningkatan dan penurunan nilai Void in the minerale aggregate (VMA) seiring dengan Variasi kadar limbah karbitnya. adapun hubungan antara VMA dengan limbah karbit dapat dilihat pada Gambar 4. 


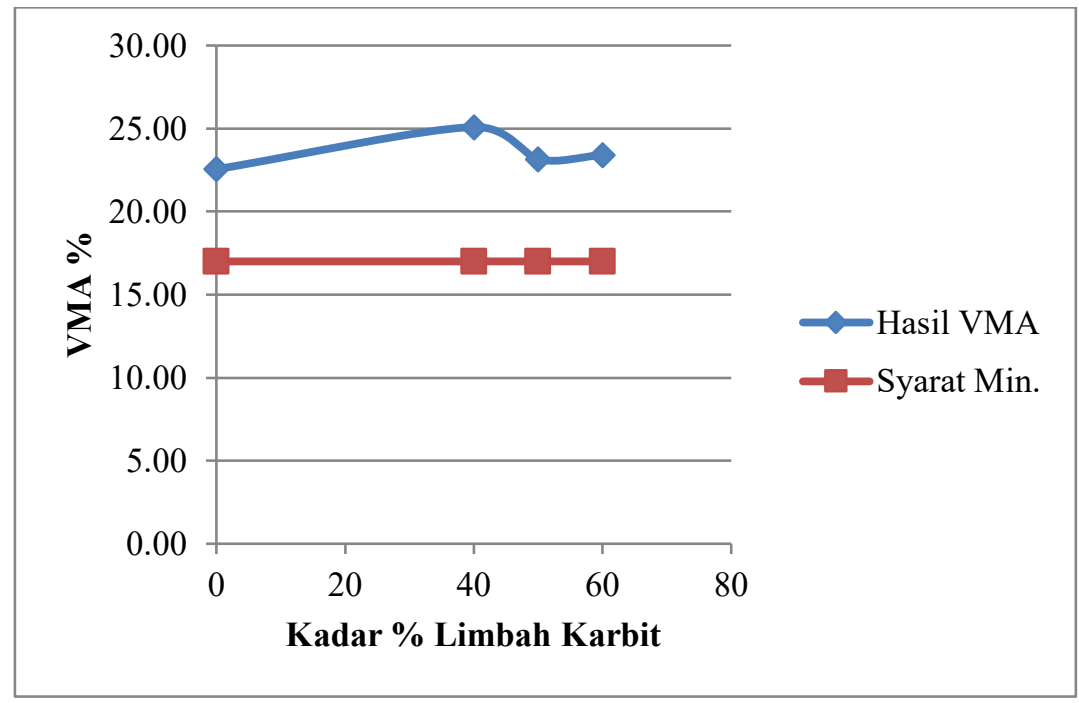

Gambar 4. Grafik hubungan antara VMA dengan limbah karbit

Grafik diatas Menunjukkan bahwa hasil penelitian substitusi limbah karbit mempengaruhi nilai Void in the minerale aggregate (VMA). sementara ketentuan Standart Spesifikasi Umum Divisi 6 : Perkerasan Aspal untuk Void in the minerale aggregate (VMA) minimal $18 \mathrm{~kg}$. sehingga Void in the minerale aggregate (VMA) pada variasi $40 \%$ 60\% telah memenuhi Standart Spesifikasi Umum Divisi 6 : Perkerasan Aspal.

Faktor - faktor yang mempengaruhi naik atau turunnya nilai VMA anatara lain jumlah tumbukan, gradasi agregat dan kadar aspal. nilai VMA berpengaruh pada sifat kekedapan dan keawetan campuran terhadap air dan udara bebas serta kekakuan campuran. semakin tinggi nilai VMA berarti semakin banyak rongga dalam campuran yang terisi aspal sehingga kekedapan campuran terhadap air dan udara semakin tinggi, sebaliknya nilai VMA yang terlalu rendah menunjukkan kecilnya jumlah aspal yang mengisis rongga, sehingga akan menyebabkan lapisan kurang dapat mengikat agregat yang berakibat perkerasan mudah terjadi stripping.

\section{Tinjauan penambahan limbah karbit terhadap Voids Filled With Asphalt (VFWA)}

Hasil pengujian Voids Filled With Asphalt (VFWA) penggunaan Limbah karbit dengan variasi 0\%, 40\%,50\% dan $60 \%$ dari berat filler pada campuran aspal HRS-BC memperlihatkan peningkatan dan penurunan nilai Voids Filled With Asphalt (VFWA) seiring dengan Variasi kadar limbah karbitnya. adapun hubungan antara VFWA dengan limbah karbit dapat dilihat pada Gambar 5.

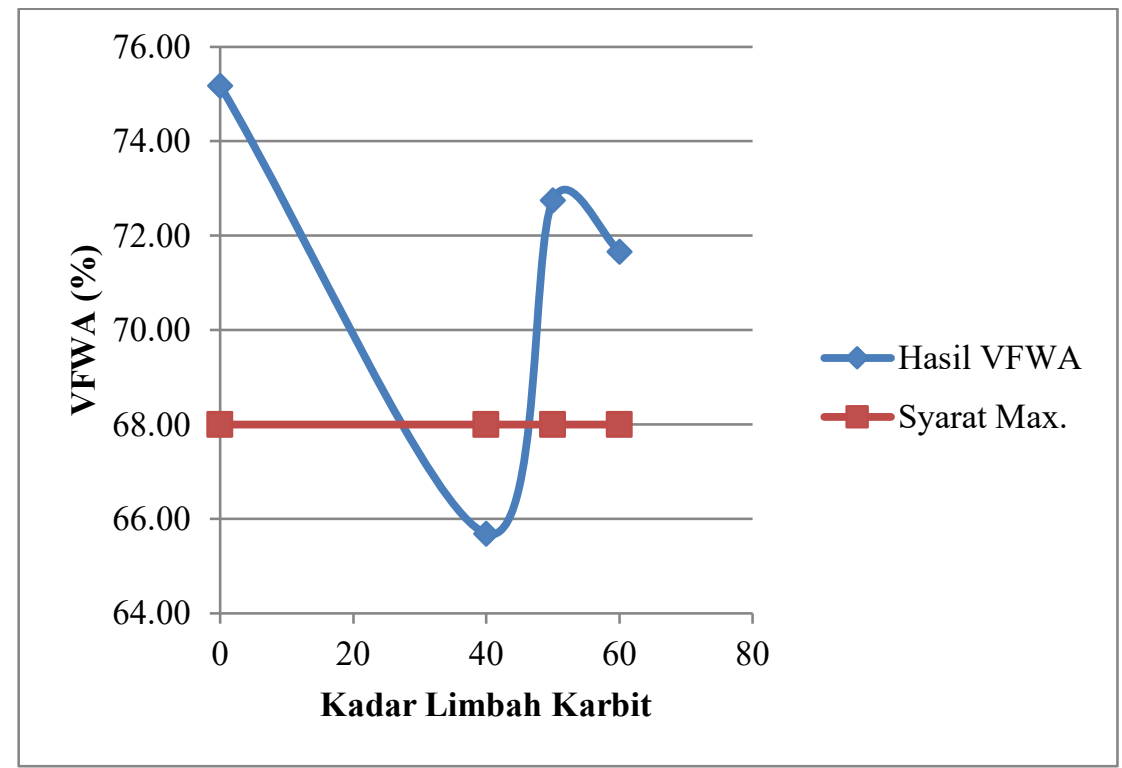

Gambar 5. Grafik hubungan antara VFWA dengan limbah karbit 
Grafik diatas Menunjukkan bahwa hasil penelitian substitusi limbah karbit mempengaruhi nilai Voids Filled With Asphalt (VFWA). berdasarkan ketentuan Standart Spesifikasi Umum Divisi 6 : Perkerasan Aspal untuk nilai Voids Filled With Asphalt (VFWA) minimal $68 \mathrm{~kg}$. sehingga hasil penelitian Voids Filled With Asphalt (VFWA) pada variasi 40\% - 60\% telah memenuhi Standart Spesifikasi Umum Divisi 6 : Perkerasan Aspal

Nilai VFWA yang besar menunjukkan jumlah aspal yang mengisi rongga besar sehingga kekedapan campuran akan meningkat. senaliknya jika nilai VFWA terlalu kecil akan menyebabkan kekedapan campuran perkerasan semkain kecil dan aspal dalam campuran akan teroksidasi dengan udara dan keawetan atau kekedapan campuran akan berkurang. sehingga aspal tidak mengikat dengan baik.

\section{Tinjauan penggunaan limbah karbit terhadap Void in the mix (VIM)}

Hasil pengujian Void in the mix (VIM) penggunaan Limbah karbit dengan variasi 0\%, 40\%,50\% dan $60 \%$ dari berat filler pada campuran aspal HRS-BC memperlihatkan peningkatan dan penurunan nilai Void in the mix (VIM) seiring dengan Variasi kadar limbah karbitnya. adapun hubungan antara VIM dengan limbah karbit dapat dilihat pada Gambar 6.

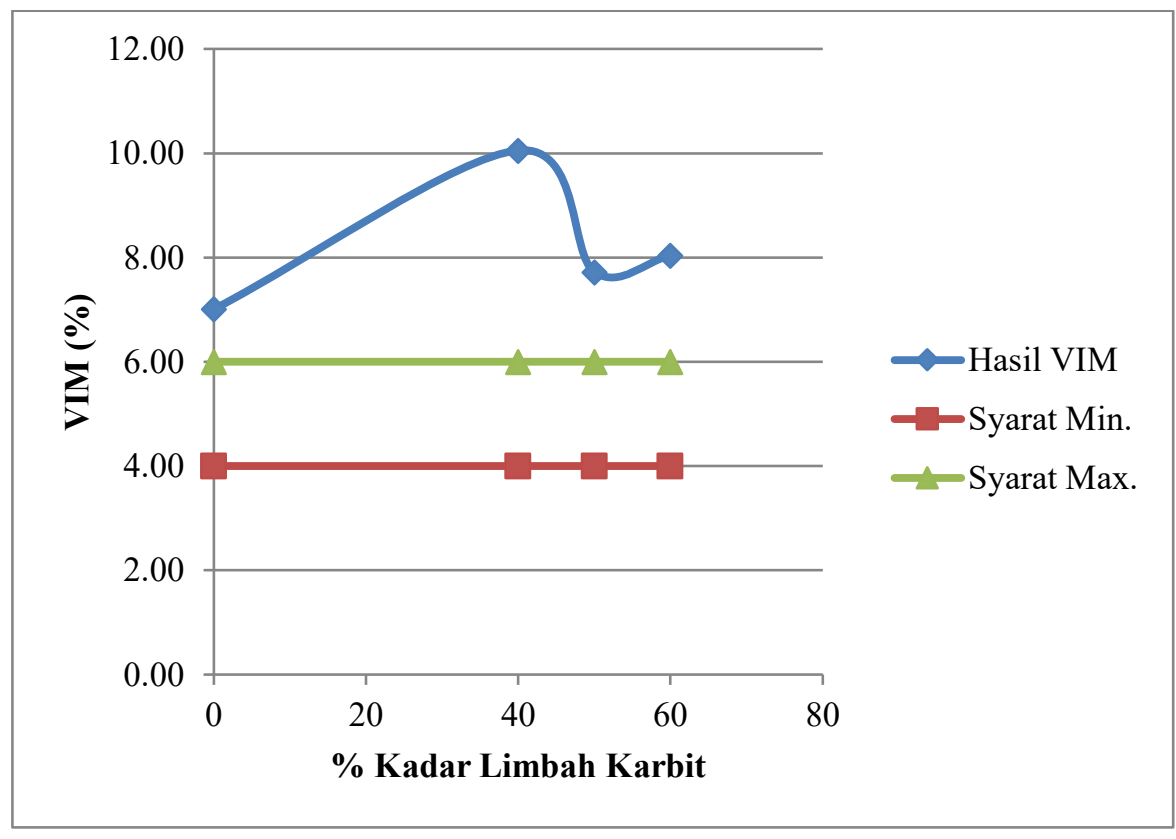

Gambar 6. Grafik hubungan antara VIM dengan limbah karbit

Grafik diatas Menunjukkan bahwa substitusi limbah karbit mempengaruhi nilai Void in the mix (VIM) dan dari hasil percobaan pada variasi 40\% - 60\% mengalami peningkatan. sementara untuk ketentuan dan syarat dari Void in the mix (VIM) minimal 4 dan maksimal $6 \mathrm{~kg}$. sehingga Void in the mix (VIM) dari filler yang telah disubstitusi dengan limbah karbit pada variasi 40\% - 60\% tidak memenuhi Standart Spesifikasi Umum Divisi 6 : Perkerasan Aspal.

Besarnya nilai VIM sangat dipengaruhi oleh kadar aspal, cara pemadatan dan gradasi batuan. Kenaikan nilai VIM menunujukkan campuran banyak terdapat rongga sehingga campuran kurang terhadap kekedapan air dan udara, sehingga campuran akan lebih mudah diresapi air, hal ini dapat menyebabkan kerusakan pada lapis perkerasan.

\section{Tinjauan penggunaan limbah karbit terhadap kelelehan (Flow)}

Hasil pengujian Kelelehan (Flow) penggunaan Limbah karbit variasi 0\%, 40\%,50\% dan 60\% dari berat filler pada campuran aspal HRS-BC memperlihatkan penurunan nilai kelelehan (Flow) seiring Variasi kadar limbah karbitnya. adapun hubungan antara kelelehan (Flow) dengan limbah karbit dapat dilihat pada Gambar 7. 


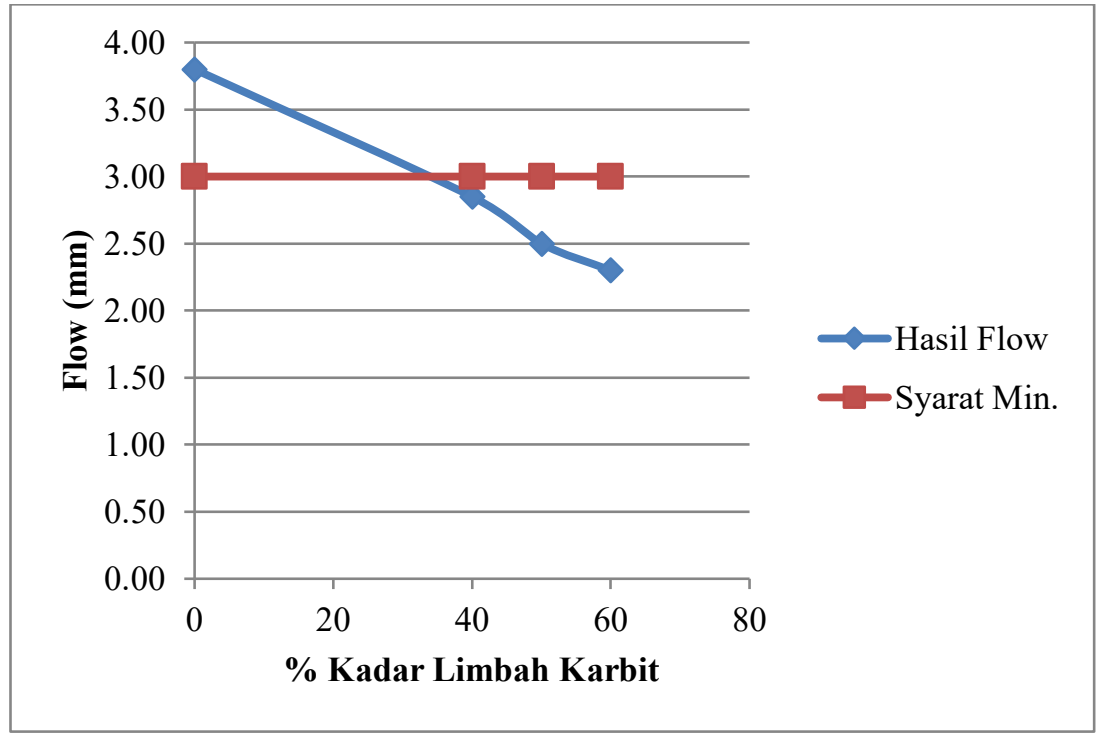

Gambar 7. Grafik hubungan antara Flow dengan limbah karbit

Grafik diatas Menunjukkan bahwa substitusi limbah karbit mempengaruhi nilai (Flow) dan dari hasil percobaan variasi $40 \%$ - 60\% nilai flow mengalami penurunan dengan nilai $\leq 3,0$. sementara untuk ketentuan dan syarat dari (Flow) minimal 3,0 mm. sehingga nilai kelelehan (flow) dari dari hasil percobaan tidak memenuhi Standart Spesifikasi Umum Divisi 6 : Perkerasan Aspal

Faktor yang mempengaruhi kenaikan serta penurunan pada nilai flow yaitu semakin banyak substitusi kadar limbah karbit, maka semakin berkurang kadar aspal sehingga mengakibatkan perekatan agregat dan aspal tidak sempurna dan menyebabkan ketegasan.

\section{Tinjauan penggunaan limbah karbit terhadap Marshall Quotient (MQ)}

Hasil pengujian Marshall Quotient (MQ) penggunaan Limbah karbit variasi $0 \%, 40 \%, 50 \%$ dan $60 \%$ dari berat filler pada campuran aspal HRS-BC memperlihatkan peningkatan dan penurunan nilai Marshall Quotient (MQ) seiring dengan Variasi kadar limbah karbitnya. adapun hubungan antara Marshall Quotient (MQ) dengan limbah karbit dapat dilihat pada Gambar 8.

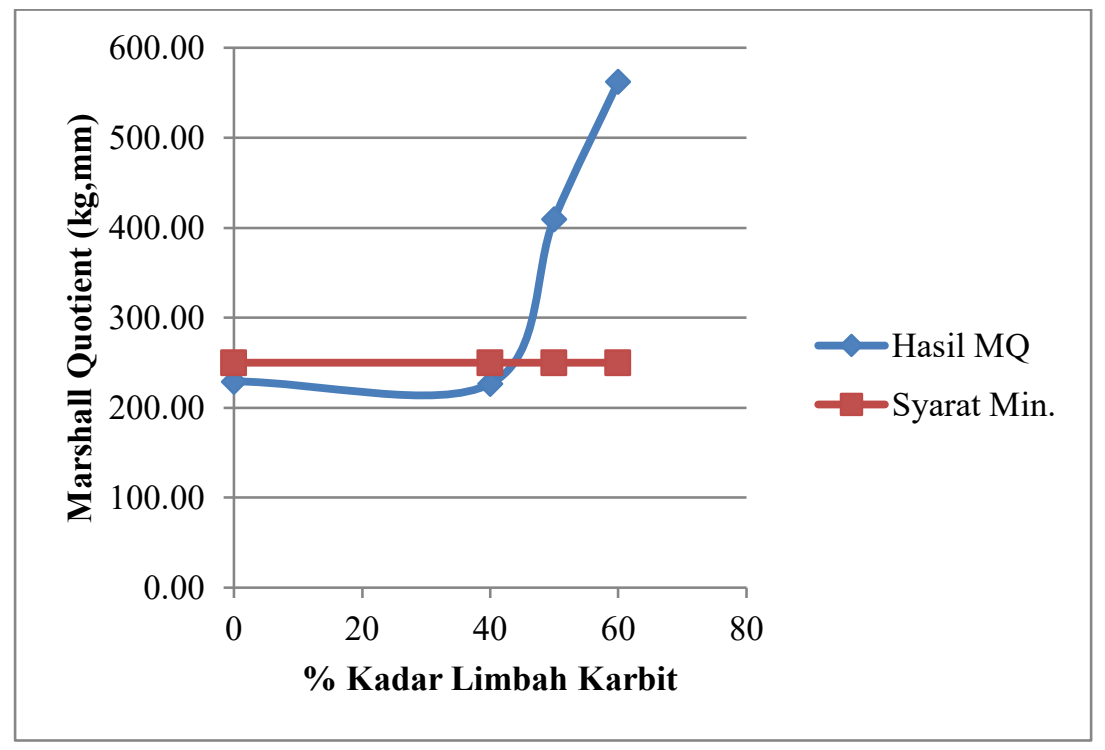

Gambar 8. Grafik hubungan antara Marshall Quotient (MQ) dengan limbah karbit

Grafik diatas Menunjukkan bahwa substitusi limbah karbit mempengaruhi nilai Marshall Quotient $(M Q)$ dan dari hasil percobaan pada variasi $40 \%$ nilai variasi mengalami penurunan, sedangkan pada kadar $50 \%-60 \%$ nilai Marshall Quotient (MQ) mengalami peningkatan. sementara untuk ketentuan dan syarat dari Marshall Quotient 
(MQ) minimal $250 \mathrm{~kg} / \mathrm{mm}$. sehingga Marshall Quotient (MQ) variasi 40\% tidak memenuhi Standart Spesifikasi Umum Divisi 6 : Perkerasan Aspal. sedangkan Marshall Quotient (MQ) variasi 50\% dan 60\% telah memenuhi Standart Spesifikasi Umum Divisi 6 : Perkerasan Aspal

kenaikan dan penurunan nilai MQ dipengaruhi stabilitas dan flow. pada campuran semakin tinggi nilai stabilitas dan semakin rendah nilai flow maka nilai MQ semakin tinggi atau sebaliknya.

\section{KESIMPULAN DAN SARAN}

\section{Kesimpulan}

Kesimpulan yang dapat diperoleh dari penelitian ini diantaranya :

1. Hasil dari Pengujian substitusi filler dengan variasi limbah karbit $0 \%, 40 \%, 50 \%$ dan $60 \%$ dari berat filler untuk nilai marshall properties didapatkan hasil penelitian pada Tabel 7.

Tabel 7. Hasil pengujian Marshall Test dengan variasi limbah karbit pengganti filler

\begin{tabular}{ccccccc}
\hline $\begin{array}{c}\text { Limbah Karbit } \\
(\%)\end{array}$ & $\begin{array}{c}\text { Stabilitas } \\
(\mathrm{kg})\end{array}$ & $\begin{array}{c}\text { VFWA } \\
(\mathrm{kg})\end{array}$ & $\begin{array}{c}\text { VMA } \\
(\mathrm{kg})\end{array}$ & $\begin{array}{c}\text { VIM } \\
(\mathrm{kg})\end{array}$ & $\begin{array}{c}\text { Flow } \\
(\mathrm{mm})\end{array}$ & $\begin{array}{c}\text { MQ } \\
\mathrm{kg} / \mathrm{mm}\end{array}$ \\
\hline $0 \%$ & 871,13 & 75,18 & 22,55 & 7,01 & 3,80 & 229,29 \\
$40 \%$ & 629,20 & 65,69 & 25,09 & 10,05 & 2,85 & 226,52 \\
$50 \%$ & 1011,76 & 72,75 & 23,15 & 7,72 & 2,50 & 410,00 \\
$60 \%$ & 1291,26 & 71,67 & 23,41 & 8,04 & 2,30 & 562,35 \\
\hline Spesifikasi & Min 800 & Min 68 & Min 17 & Min 4 Max 6 & Min 3,0 & Min 250 \\
\hline Jumlah Tumbukan & \multicolumn{7}{c}{$2 \times 75$} \\
\hline Kadar Aspal (\%) & \multicolumn{7}{c}{$6,5 \%$} \\
\hline
\end{tabular}

2. Substitusi filler dengan penggunaan limbah karbit terhadap campuran aspal HRS-BC ternyata mempengaruhi hasil marshall properties. hasil pengujian substitusi campuran yang paling memenuhi spesifikasi adalah pada campuran limbah karbit kadar 60\% yakni hasil stabilitas, VFWA,VMA, dan Marshall Quotient. namun pada kadar $60 \%$ ada yang tidak memenuhi Spesifikasi Umum Divisi 6 : Perkerasan Aspal yaitu hasil Flow dan nilai VIM.

\section{Saran}

Saran yang diperoleh dari penelitian ini diantaranya :

1. Sebelum memulai pengujian, disarankan untuk dilakukan pengecekan terlebih dahulu terhadap kevalidan peralatan yang akan digunakan untuk penelitian. karena hal ini berpengaruh terhadap proses pembuatan benda uji campuran aspal HRS-BC.

2. Diperlukan ketelitian dan perhitungan yang baik dalam penentuan komposisi aspal dan pembuatan campuran kerja aspal HRS-BC agar hasil penelitian tersebut dapat maksimal dan tidak terjadi kesalahan serta penelitian dapat sesuai standart yang berlaku

\section{DAFTAR PUSTAKA}

BSN. (2008a). SNI 1969-2008. cara uji berat jenis dan penyerapan air agregat kasar. Badan Standardisasi Nasional. Jakarta.

BSN. (2008b). SNI 1970-2008. cara Uji Berat Jenis Dan Penyerapan Air Agregat Halus. Badan Standardisasi Nasional. Jakarta.

BSN. (2011a). SNI 2433-2011. cara Pengujian Titik nyala dan Titik Bakar. Badan Standardisasi Nasional. Jakarta. BSN. (2011b). SNI 2434-2011. Cara Pengujian Titik Lembek Aspal. Badan Standardisasi Nasional. Jakarta.

BSN. (2011c). SNI 2441-2011. cara Pengujian Berat Jenis Aspal. Badan Standardisasi Nasional. Jakarta. BSN. (2011d). SNI 2456-2011. Cara Pengujian Penetrasi Aspal. Badan Standardisasi Nasional. Jakarta. Hardiyatmo, H. C. (2015). PEMELIHARAAN JALAN RAYA (Gadjah Mada University Press (ed.); kedua). Agustus 2015. 
Kementerian Pekerjaan Umum dan Perumahan Rakyat. (2016). Spesifikasi Umum Divisi 6 Perkerasan Aspal. 1118.

Mahendra, P., \& Risdiato, Y. (2019). PEMANFAATAN LIMBAH KARBIT SEBAGAI MATERIAL PENGGANTI SEMEN TERHADAP KUAT TEKAN BETON NORMAL Pandu Mahendra Yogie Risdianto. 2 No. 2, 1-7.

Satyagraha, F. (2018). PENGARUH PENAMBAHAN LIMBAH BAN DALAM BEKAS KENDARAAN DAN FILLER LIMBAH KARBIT PADA LASTON (AC-BC) TERHADAP KARAKTERISTIK MARSHALL (pp. 1-93). Program Studi Teknik Sipil Fakultas Teknik Universitas Negeri Yogyakarta.

Wiharto, M. (2015). Studi Penggunaan Limbah Las Karbit Sebagai Substitusi Sebagian Aspal Shell Pen 60. Xx(x), $1-12$.

Zakir, R. F., Naumar, A., \& Indra, K. (2020). PENGARUH PENGGANTIAN FILLER CAMPURAN ASPAL BETON LAPISAN AUS AC-WC. 2(Vol. 2 No. 2 (2020): Executive Summary Tugas Akhir Teknik Sipil Wisuda Akademik 74). 
